\title{
Does hyperoxemia since pre hospital emergency medicine influence prognostic in patients with septic shock?
}

\author{
L. Castres Saint Martin ${ }^{1}$, R. Jouffroy ${ }^{1}$, P. Philippe ${ }^{1}$, R. Idialisoa ${ }^{1}$, P. Carli ${ }^{1}$ and B. Vivien ${ }^{1}$ \\ ${ }^{1}$ Intensive Care Unit, Anesthesiology and SAMU - Necker-Enfants malades hospital, \\ University Paris Descartes - APHP - 149 rue de Sèvres 75015 Paris - France
}

\section{INTRODUCTION}

Deleterious effects of prolonged hyperoxemia exposition well established especially after cardiac arrest and brain trauma [1]. Definition of hyperoxemia is not consensual despite a threshold of $100 \mathrm{mmHg}$ partial for the British Thoracic Society [2].

The aim of this study was to determine if there is an association between level of $\mathrm{PaO} 2 / \mathrm{FiO} 2$ ratio $(\mathrm{P} / \mathrm{F})$ and mortality at day $28(\mathrm{D} 28)$.

\section{METHOD}

Monocentric retrospective observational study in a university teaching hospital general adult intensive care unit (ICU) including 45 patients with a $\mathrm{PaO} 2$ measurement at ICU admission.

\section{RESULTS}

Origins of sepsis were mainly pulmonary (72\%) and urinary (16\%). Average $\mathrm{P} / \mathrm{F}$ ratio at the time of admission in ICU was $200 \pm 88 \mathrm{mmHg}$.

When $\mathrm{P} / \mathrm{F}$ ratio is higher than 225 , the $\mathrm{D} 28$ mortality risk is multiplied by 3.9 : $\mathrm{OR}=3.9[1.3-12.2] ;(\mathrm{p}=0.04)$.

When $\mathrm{P} / \mathrm{F}$ ratio was lower than 200 , we observed an $85 \%$ decrease of D28 mortality: $\mathrm{OR}=0.15[0.04-0.47](\mathrm{p}=0.0077)$.

\section{DISCUSSION}

In this study, we observed a strong association between hyperoxemia during prehospital cares and D28 mortality for patients admitted into ICU for septic shock requiring mechanical ventilation since pre-hospital stage. A P/F ratio lower than 200 at ICU admission of patients with septic shock requiring mechanical ventilation and sedation seems to be a target. $\mathrm{PaO} 2$ is a parameter that could be obtained simply and quickly to adjust oxygen dose since pre hospital care and to avoid toxic effects of hyperoxemia. In order to confirm those results and to define the "target" value of the oxygen dose for those patients, larger multicentric prospective studies should be performed.
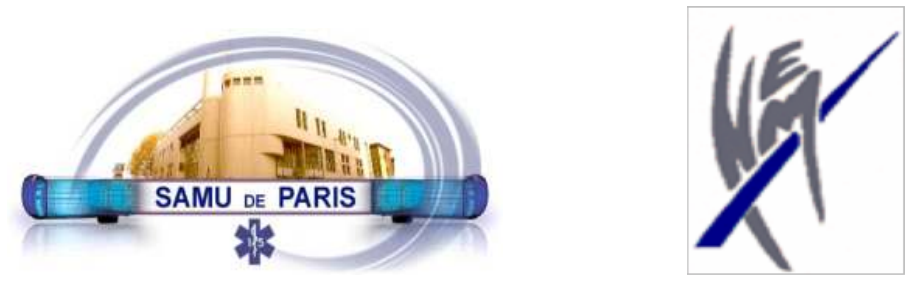